\title{
Politics and problematics of the definition and categorization of ethnicity in Nepal
}

- Ramesh Pokharel

\section{Introduction}

Race is a product of social conflicts between different groups of people, and hence it is guided by the interests and politics of privileging some groups over the others. Omi and Winant (2002) define race as "a concept which signifies and symbolizes social conflicts and interests by referring to different types of human bodies" (p. 123). Race, when defined loosely, is taken interchangeably with ethnicity. According to Miles \& Brown, ethnicity is a concept related to race (2003). By and large, it denotes a category that distinguishes groups based on sociocultural characteristics, such as ancestry, language, religion, custom and lifestyle. However, like race, ethnicity does not denote innate or inherent attributes of humans. Rather, it is a relational concept that sets one group of people apart from another - a process of constructing differences.

The people in power, according to Teun van Dijk, "mark social boundaries and reaffirm social and ethnic identities, and selfattribute moral superiority to their own group" (1992, p. 310) thereby strategically denying their engagement in constructing difference. The basic strategy used by them is "positive selfpresentation" known as theory of denial. Denial, in van Dijk's words, is used by the elite members of the group in power or the group itself as a "strategy of defense, as well as a part of the strategy of positive self-presentation" (p. 308). The method inherently carries a strong tendency to "reject any accusation or suggestion of prejudice, discrimination or racism," and "the more racist the opinions professed, the more insistent are the denials of racism" (p. 318-319). According to William's reading of Gramsci, civil society corresponds to hegemony, 
while political society or the "state" corresponds to "direct domination" or "command" (1985, p. 144). As such, there is nothing "arbitrary" about the choice of the dominant language or culture. These choices are always guided by political motives elsewhere and in Nepal too that has worked through ages.

Nepal, a multi-ethnic, multi-linguistic, and multi-cultural country, has a different history of the construction of ethnicity and race (though race as it is taken in the world does not exist in Nepal). For long, ethnicity was a matter of imposed categorization on some ethnic groups having different origin, language, culture, and tradition from the dominant groupsBrahman and Chhetri. As the ethnic groups became conscious of their marginalization, they formed ethnic organizations and started fighting for their rights. With the revival of democracy and formation of a republican state, the ethnic groups in Nepal have themselves defined and categorized ethnicity by associating it with indigenity. In this paper, I will attempt to critique and analyze the politics and problematics of the construction of ethnicity as done by the ethnic groups at present time. While so doing, I will engage in critical discourse analysis of the definition and categorizations of ethnic groups.

\section{History of the construction of race/ethnicity}

The birth of race in global context takes us back to the process of colonization, i.e., the European expansion to various parts of the world which was accompanied by their categorization of the Other as inferior. Even the $18^{\text {th }}$ century science emphasized upon the biological categories of human beings in order to perpetuate a hierarchy of superiority/inferiority. Post-colonial society rejected the biological differences as the fundamentals of race. In contemporary world, racial difference has been increasingly replaced by cultural difference, which is used to differentiate, exclude, or privilege certain groups of people.

The history of construction of ethnicity in Nepal is different from that of colonized spaces as Nepal never experienced 
external political colonization. However, the ruling class always had the tendency to other some ethnic groups, and thus internal colonization existed which constructed race as ethnicity based on Hindu caste system that was/is dominant in Hinduism. In the period from $10^{\text {th }}$ to $18^{\text {th }}$ Century, the Kathmandu Valley was ruled by the Malla dynasty, and it was during the reign of Jayasthiti Malla (r. c. 1382-95) a legal and social code strongly influenced by contemporary Hindu principles was introduced (Malla era, 2011). The provisions categorized and systematized people in four categories (Brahmin, Chhetri, Baisya, and Sudra) thereby creating caste based hierarchies. While these strata were limited in Kathmandu valley in Malla era, the notion expanded outside the valley with unification of Nepal in Shah Regime. Thus, right from the beginning of its unification, the modern state of Nepal has been an affair of elites belonging to some high caste Hindu groups, which, at the same time, marginalized the numerous ethnic groups and the lower Hindu castes, and thus prevented them from every kind of participation. "This status," according to Kraemer, "was codified by the muluki ain of 1854 and it was further intensified in recent times by the unitarian politics of King Mahendra's panchayat system" (1998). The argument what Villanueva (1993) suggests in "language is also race in America" (p. xii) could be extended to some extent in the construction of ethnicity in Nepal because those people who did not speak Nepali language at their mother tongue were othered systemically and were deprived of opportunities.

The ethnic elites became aware of this othering only in the late seventies and early eighties, and their growing selfconsciousness ultimately led to the formation of ethnic organizations that forced constitutional changes which eventually led to form Forum for the Rights of All Nationalities in 1986 from diverse ethnic groups. The active participation of ethnic organizations in the people's movement of 1990 showed their concern not only for political system but also sociopolitical modifications and economic participation. 
As stated above, the political movement of 1990 and the political changes it brought along fostered consciousness among ethnic groups and thus formed organizations "to preserve their cultural identity and to fight for equal rights and participation in the Nepali state" (Kraemer, 1998). After the formation of Nepal as a republic state, the ethnic groups are naturally very conscious of their rights and are active in reinterpreting and rewriting the history from their perspectives based on the idea of race, language, religion and territory. They still claim that there is no equal participation of ethnic groups in decision-making bodies. While so doing, they have defined and categorized ethnic groups from their own perspectives, which however, contradicts with the universal idea of indigenity. In the following section, I will quote their definition and categorizations of ethnicity followed by an analysis of the politics and problematics of the definition and categorizations based on critical discourse analysis.

\section{Definition and categorization}

The National Foundation for Development of Indigenous Nationalities (NFDIN) categorizes ethnic group as having following characteristics, which do not fall under the conventional fourfold Hindu Varna system:

○ A distinct collective identity,

o Own language, religion, tradition, culture and civilization,

- Own traditional egalitarian social structure,

o Traditional homeland or geographical area,

$\circ$ Written or oral history,

o Having 'We' feeling,

o Has had no decisive role in the politics and government of modern Nepal,

○ Who are the indigenous or native peoples of Nepal, and

○ Who declares itself as Janajati.

(Source: LAHURNIP-- http://www.lahurnip.com/index.php) 
Nepal Federation of Indigenous Nationalities has categorized ethnic groups as following:

○ Endangered Group (Kusunda, Bankariya, Raute, Surel, Hayu, Raji, Kisan, Lepcha, Meche, Kuswadiya)

o Highly Marginalized Group (Majhi, Siyar, Lhomi (shinsaba), Thudam, Dhanuk, Chepang, Santhal, Jhagad, Thami, Bote, Danuwar, Baramu)

- Marginalized Group (Sunuwar, Tharu, Tamang, Bhujel, Kumal, Rajbangshi, Gangaai, Dhimal, Bhote, Darai, Tajpuriya, Pahari, Topkegola, Dolpo, Fri, Mugal, Larke, Lohpa, Dura, Walung)

○ Disadvantaged Group (Chhairotan, Tanbe, Tingaule Thakali, Baragaunle Thakali, Marphali Thakali, Gurung, Magar, Rai, Limbu, Sherpa, Yakkha, Chhantyal, Jirel, Byansi, Yolmo)

o Advanced Group (Newar, Thakali).

(Source:NFIN-http://www.nefin.org.np/indigenousnationalities/categorization.html)

The above mentioned definition and categorizations of ethnicity are based on the arguments of race, religion, language and tradition. The ethnic elites, in the process of defining and categorizing, are trying to reconcile their groups with their diverse cultural values of other ethnic groups which are dissimilar in order to seek for unity among them culturally while divorcing them from the culture of the dominant groups, which seems to be naturally very difficult task because the culture of some ethnic people is so intricate with that of dominant groups that any attempt to divorce them could be futile and sometimes counter-productive. The forceful separation or yoking together diverse cultures is fundamentally based on political motives. At the same time, they are engaged in looking for new ways of interpretation of tradition.

The elites' first argument grounds on the issue of race. Most of Nepal's ethnic groups belong to the Tibeto-Mongolian stock 
with some exceptions of Newars and a few Tarai groups who have relation to Indian Mundas or Southeast Asian groups. Based on the principle of majority, the ethnic elites stress on their common Tibeto-Mongolian origin, and point out their differentness from the high Hindu castes dominating in politics, society and economy in order to provide a common racial bond for Nepal's divergent ethnic groups, which, in fact, does not necessarily embrace all ethnic groups.

The elites' second argument concerns religion; it has been used as one of the fundamental pillars of the ethnic culture and hence the springboard for ethnic reconciliation and separation from the ruling elites in order to fight for ethnic rights. They claim that all ethnic groups of the country are Buddhists or, at least, are influenced by Buddhist thought in order to bring them in contrast to the high Hindu castes. But the nexus, to use Kraemer's idea, is not so linear, "The religious base of most ethnic cultures is not Buddhism but some kind of animism or shamanism which, within many ethnic cultures of the pahad region, has been overlapped by Buddhist influences with different intensity" (1998). The premise of religion, in fact, would be insufficient to categorize ethnicity in terms of religion because the flat generalizing tendency does not rightly capture the essence of intricacy and complexity of religious practices ethnic groups are engaged in. Likewise, some ethnic groups have adopted a number of Hindu values and practices because of their long running contacts with the neighboring Hindu castes and some Hindus have incorporated the values of Buddhism as well. So, there is a kind of historical overlapping and reciprocal influencing of religions that has made the questions of religion very intricate and complex.

Another argument of the ethnic elites is language. They argue that Nepali language has come to represent capital and power and symbolizes a kind of dividing rod of class and racial disparity. The imposition of Nepali as an official language has played an instrumental role to enforce Hindu politics in order to cause a steady decline of the number of people speaking ethnic 
languages. They argue expounding upon Ibrahim, and Kubota \& Lin that race, language and identity are linked (2009; 2009). Similar is the idea of Grant and Lee (2009): "hegemonic ideologies of language and of the relationships between language, race, and social class have played an important role in official construction of difference" (pp. 44-45). Following this take, the ethnic groups in Nepal have taken language as their identity construction. The case, however, is different; majority of them speak Tibeto-Burman languages which distinguish them from the Indo-Aryan Hindu population speaking Nepali. Realizing this politics of language, the current endeavor of the ethnic elites to revive their mother tongues and, if necessary, equip them with script and literature has helped to construct their identity. However, in the process, to use Kraemer's insight, they have downplayed the cultural aspect of language, "[...] by using it as a fundamental argument in their dialogue with the state, the ethnic organizations make it a political one" (1998).

\section{Problematics and politics of the definition and categorization of ethnicity}

I see problems in their definition and categorization of ethnicity and indigenity, because the process which is falsely based on indigenity not only contradicts with the history of composition of Nepalese population, but also indirectly mediates the definition of indigenous people. The discourse, in other words, avoids viewing it in relations to other discourses. As Fairclough (2010) agrues, "Discourse is not simply an entity we can define independently: we can only arrive at an understanding of it by analysing sets of relations" (p. 3). In the following part, I would like to do Critical Discourse Analysis (hereafter CDA) looking at the discourse in relations to other discourses. While so doing, I will shed light on the history of the construction of Nepalese population; and on that basis I will analyze the problematics and politics of the construction of ethnicity in Nepal as done by ethnic group. 
Looking at the discourse of the definition and categorization of ethnicity in relations to its dialectical relations with historical discourse, we find the categories much problematic because it does not only politicize a concept; rather it provides historically erroneous knowledge. Nepali population, as classified by political scientists Joshi and Rose broadly fall "into three major ethnic groups in terms of their origin: Indo-Nepalese, TibetoNepalese, and indigenous Nepalese" (qtd. in Savada, 1991). The history different groups also support this argument. The first group of people, all Hindu, migrated to Nepal from India when there was Hindu/Muslim conflict and settled in the more fertile lower hills, river valleys, and later on in Tarai plains, whereas the second major group that consisted of communities of Tibeto-Mongol origin migrated to Nepal many years earlier than the Indo-Nepalese from the north (Tibet) and settled occupying the higher hills from the west to east. The third and much smaller group (the indigenous Nepalese) comprised a number of tribal communities, such as the Tharus and the Dhimals of the Tarai, and Kusunda, Raute, Surel, Hayu, Raji, Kisan, Lepcha, Meche, Kuswadiya, Majhi, Chepang, and the like of the hills may be remnants of indigenous communities whose habitation predates the advent of Indo-Nepalese and Tibeto-Mongol origin. In Savada's account, "Even though Indo-Nepalese migrants were latecomers to Nepal relative to the migrants from the north, they have come to dominate the country not only numerically, but also socially, politically, and economically" (1991).

The Indo-Nepalese group can be categorized into two groups: the first group migrated to Nepal and moved to the safe sanctuaries of the Nepal hills several hundred years ago, in the wake of the Muslim invasions of northern India; the second group settled in the Tarai, most of them are relatively recent immigrants, have been peripheral to the political power structure. The first group of migrants, which, in the early 1990s, made up more than 50 percent of the total population of Nepal, have same language, religion, social organization, and physical appearance, managed to achieve early dominance over the 
native and northern migrant populations till now, largely because of the superior formal educational and technological systems they brought with them. The Brahman and Chhetri, the hill group of Indian origin, primarily composed of descendants of high-caste Hindu families, also had close association with royal families. According to Joshi and Rose "These families, mostly of Brahman and Kshatriya [Chhetri] status, have spread through the whole of Nepal with the exception of the areas immediately adjacent to the northern border. They usually constitute a significant portion of the local elites and are frequently the largest landowners in an area" (cited in Saveda, 1991). As a result their overall domination has had tremendous significance in terms of ethnic power structure, and the main reason of ethnic movement in Nepal now after the revival of democracy and establishment of republic state.

The Tibeto-Nepalese, as stated earlier, settled on the north, and were politically, socially and economically marginalized by the Indo-Nepalese group from the right beginning. This group consists of many castes/ethnic groups, namely, Sherpa, Tamang, Rai, Magar, Limbu, Gurung, and Thakali, who define them as ethnic group, janajati, and indigenous people. Now a big question emerge: what are the criteria to categorize ethnicity and indigenity? The universally accepted criterion for defining indigenous people is that the people who inhabit in a place from the time immemorial as their native land, who are not immigrants in that land. I will talk about the concept of indigenity, its categorization and politics and problems of the category in Nepal later.

Now I will move to talk on the construction of ethnicity in Nepal based on CDA that analyzes "dialectical relations between discourse and other objects, elements or moments, as well as analysis of the 'internal relations' of discourse" (Fairclough, 2010, p. 4). How do they categorize themselves as ethnic group? Is it socio-political and economic aspect? Do the people who are socially, politically and economically deprived of belong to ethnic group? If this marginalization is the basis of 
belonging to ethnicity, do all the categories as stated above are marginalized people? They are not. For example, Newar and Thakali, who are categorized as advanced ethnic groups, are not marginalized groups. They are in fact advanced and privileged group of in Nepal.

Newars migrated from India and settled in Kathmandu valley, the center of business and market from the ancient time to now, and dispersed later on in other areas basically in the town with the expansion of trade and business. Some of the Newars are also descendants of royal family and so they have close relation with power. Because of economic and political privilege, according to a 1991 newspaper report, 13 percent of the post in civil service, the army, and the police were held by Kathmandu valley Newars, whose share of the total population was merely 3 percent, whereas 80 percent of those posts were held by the Brahmin and Chhetris of the hills, who comprised less than 50 percent of the population (qtd. in Saveda, 1991). Newars also have strong hold in government cabinet and business and trade sector.

Similarly, Thakalis from the Mustang District adjacent to Manang have moved to Pokhara, a major urban center in the hills about 160 kilometers west of Kathmandu, and to Butawal and Siddhartha Nagar, two important urban areas in the central part of the Tarai, directly south of Pokhara. They are successful businessmen and have economic privilege.

There is a tension in Nepali ethnic groups in conceptualizing ethnicity. While on the one hand ethnic people believe that ethnicity is socio-political racist construct to divide humans and rule, which implies that there is no such difference among people, on the other, they own these differences for political purpose. There is a tendency among some groups to categorize themselves as ethnic group for political purpose, e.g. Newars and Thakalis categorized themselves as ethnic groups. There exists a distinction between dominant (Newar, Thakali, Sherpa, Tamang, Magur, Rai, Limbu, Gurung) and dominated ethnic 
groups (the Other) who belong to endangered group, highly marginalized group and marginalized group in the above categories. As convention, a few ethnic groups are in power, and so it is not inclusive, hence perpetuation of hierarchies among ethnic groups.

To go back to the question of indigenity, which I briefly mentioned above, it is erroneous to define all ethnic groups as indigenous people because all ethnic groups as categorized above do not belong to indigenous people's category because some of them are migrants to Nepal from Tibet. Many groups of people categorized as indigenous Nationalities are not in fact indigenous, e.g. Sherpa, Tamang, Magar, Gurung, Rai, Limbu, Thakai belong to Tibeto-Mongol origin, whereas Newars belong to Indo-Nepalese origin. Ethnicity and indigenous nationalities are not same. To define them loosely in one category is solely based on political motive-the politics of inclusion and exclusion.

To define ethnicity loosely as indigenous nationalities, adibasi janjati, is problematic. One of the characteristics of ethnic group (who has had no decisive role in the political and government of modern Nepal) does not apply to all ethnic groups. For example, as stated above, Newars have representation in government more than any other groups (even Brahman and Chhetri) and so they have decisive role in policy making. Equally problematic is the last category of definition (who declares itself 'Janajati'). If a group can be 'Janajati' (ethnic group), can Chhetri also be ethnic group in the context when their demand to include them in this category has been accepted by the government?

\section{Conclusion}

In contemporary Nepali society, racialization among ethnic group has political purpose and they adopt psychological and cultural strategies to accommodate and resist the distinction. They resort to what Kubota \& Lin say strategic racialization, 
"to construct their own identity in positive terms for the purpose of resistance" (, 2009, p. 5). And, interestingly, especially among the ethnic leaders double standard in their perception of (anti)Hinduism is obviously perceptible: while among ethnic groups they attack Hinduism vehemently and argue for not celebrating Hindu festivals, they celebrate these festivals privately and officially.

Infiltration of some advanced groups into ethnic groups and infiltration of some ethnic groups into indigenous group is fundamentally done only for political purpose. While this infiltration brings political, social and economic problems because the real ethnic groups and real indigenous groups always lag behind in the race of cashing opportunity with the advanced groups, it develops a tendency to define and categorize them as backward group which subsides the real problem thereby benefiting only advanced groups within that category. This helps the advanced groups and the elites in those groups benefit from the affirmative action whereas the real ethnic group and the real indigenous groups always lag behind because they cannot compete with the more advanced groups.

So, in order to address the agenda of ethnic groups and indigenous groups, it is high time to revise the construction of ethnicity and indigenity from normative perspective to capture the essence of the very concept in such a way that it benefits the real ethnic and indigenous groups. In that revision, religion cannot be fundamental basis for the construction of ethnicity and indigenity, and it should not be the space for some handful elites to do dirty politics in their favor by depriving of the real one from the benefit of affirmative action of the state.

During the process, the application of Thomas R. West's (2002) notion of "critical negation" could address the problems which have emanated from the commodification of differences in Nepali society; firstly, because it respects the cultural difference of the people thereby giving equal value to the culture of the disenfranchised, and secondly it emphasizes on accommodating 
diversities. Ultimatley, the revision incorporates critical multiculturalism that does not simply celebrate the differences as diversity rather examines the differences of races and ethnicity by situating in historical and social context.

\section{References}

Fairclough, N. (2010). Critical discourse analysis: The critical study of language $\left(2^{\text {nd }}\right.$ ed.). London: Pearson.

Grant, R. A \& Lee, I. (2009). The ideal English speaker: A juxtaposition of globalization and language policy in South Korea and racialized language attitudes in the United States. In Ryuko Kubota \& Angel Lin (eds.) Race, culture and identities in second language education: Exploring critically engaged practice (pp. 44-63). New York: Routledge.

Ibrahim, A. (2009). Operating under erasure: Race/language/identity. In Ryuko Kubota \& Angel Lin (eds.) Race, culture and identities in second language education: Exploring critically engaged practice (pp. 176194). New York: Routledge.

Kraemer, K. H. (1998). The janajati and the Nepali state: Aspects of identity and integration. Paper presented at the First Annual Workshop of the Himalayan Studies Network, Meudon, C.N.R.S., 25-26 September. Retrieved from http://www.nepalresearch.com/publications/paris.htm

Kubota, R. \& Lin, A. (2009). Race, culture and identities in second language education: Exploring critically engaged practice. New York: Routledge.

Lawyers' Association of Human Rights of Nepalese Indigenous People. Retrieved from http://www.lahurnip.com/index.php

Malla era. (2011). In Encyclopaedia britannica. Retrieved from http://www.britannica.com/EBchecked/topic/360300 /Malla-era

Miles, R. \& Brown, M. (2003). Racism ( ${ }^{\text {nd }}$ ed.). London: Routledge.

NGO Federations of Nepalese Indigenous Nationalities. Retrieved from http://www.ngofonin.org.np/ 
Nepal Federation of Indigenous Nationalities. Retrieved from http://www.nefin.org.np/

Omi, M. \& Winant, H. (2002). Racial formation. In Philomena Essed \& David Theo Goldberg (eds.) Race critical theories (pp 123-145). Oxford: Blackwell Publishers.

Savada, A. M. (ed.). (1991). Nepal: A country study. Washington: GPO for the Library of Congress.

Van Dijk, T. A. (1992). Denying racism: Elite discourse and racism. In Essed, P. \& Goldberg, D.T. (eds.) Race critical theories, (pp. 307-324). MA: Blackwell Publishing Ltd.

Villanueva, V. (1993). Bootstraps: From an American academic of color. Urbana: NCTE.

West, R. T. (2002). Sings of struggle: The theoretical politics of cultural difference. Albany: State University of New York Press.

Williams, R. (1985) Keywords: A vocabulary of culture and society. New York: Oxford UP.

The author is a doctoral candidate and assistant instructor in the Rhetoric and Writing Studies Program, University of Texas at El Paso, USA. 